\title{
In-Vitro study to Assess Effect of a Glide Path on Canal Transportation and Centering Ratio in Double Curved canals.
}

\author{
Raghad Alhalabi ${ }^{1}$, Mohammad Salem Rekab ${ }^{1}$, Khaldaon hossein Alhroob $^{2}$, Maher Al-assaf ${ }^{3}$ \\ ${ }^{1}$ Department of Operative Dentistry, Faculty of Dentistry, Damascus University, Damascus, Syria \\ ${ }^{2}$ Department of Periodontology, Faculty of Dentistry, Damascus University, Damascus, Syria \\ ${ }^{3}$ Department of Oral Histology and Pathology, Faculty of Dentistry, Damascus University, Damascus, Syria
}

\section{Abstract}

Objective: In endodontic treatment, creating a glide path became one of the recommended essential principles to obtain a safe preparation as possible; so the aim of the research is to evaluate the efficiency of the R-Pilot system in glide path preparation within the double curved canals.

Study design: A laboratory study to assess the efficiency R-Pilot mechanical patency system on the shape marinating of the canal. Those criteria were used to evaluate the change in the original shape of the canal, Canal Transportation and Centering Ratio. The data were analyzed using SPSS V.13 program and the correlation between the variables were defined using descriptive statistics and inductive statistical tests (chi-square, T Student for independent samples, ANOVA).

Results: no significant difference between the two glide path creation systems was found in terms of the deviation amount from the canal centric. whereas, between the R-Pilot system and the manual preparation, significant difference was found in the preserving rate of the canal centric at both the coronal area and the entire canal.

Conclusion: glide path creation in the previously mentioned methods with confirmation on the importance of the mechanical patency in terms of speed, Reducing the effort and burden imposed on the practitioner compared to the use of manual files. XP Endo shaper had lower deviation values and more ability to save the shape and centric of the canal.

Keywords: endodontic treatment; canal centric; R-Pilot system; deviation amount.

Citation: Alhalabi R, et al. (2021) In-Vitro study to Assess Effect of a Glide Path on Canal Transportation and Centering Ratio in Double Curved canals. Dentistry 3000 1:a001 doi: $10.5195 / \mathrm{d} 3000.2021 .131$ Received: January 01, 2021

Accepted: February 02, 2021

Published: July 19, 2021

Copyright: (C2021 Alhalabi R, et al. This is an open access article licensed under a Creative Commons Attribution Work 4.0 United States License.

Email:dr.maher.assaf1990@gmail.com

\section{Introduction}

The primary goal of endodontic treatment is to eliminate or reduce bacteria in the root canal system as much as possible while preserving the original shape and path of the canal [1]. Where preparing the root canals is considered one of the most important steps of endodontic treatment, including the removal of infected and affected tissues within the root canal walls and obtaining smooth walls that facilitate irrigation and filling, by following the utmost ways to make the preparation as conservative as possible, enough to protect the tooth from the risk of refraction in the long term [2].

Root canals with anatomical curves are considered a challenge to the practicing physician, due to the risk of complications incidence such as instruments refraction and deviation occurrence [3], Stainless steel files tend to restore their original straight shape during the preparation of these curves, unlike nickel titanium files, which has a high elasticity, so it reduces the efforts and lateral forces applied on the canal walls as much as possible in intense curving canals [3].

The insertion of nickel titanium alloys in endodontic has allowed manufacturers to produce many instruments with high flexibility 
and resistance. Today, nickel titanium files are considered part of the daily uses of endodontists and even general practitioners with their variety of shapes, tapering, cross-sections, and many of the advantages and developments which happened to the original alloy, made it correspond with different cases [4].

Because of the sensitivity of dealing with curved canals, and because of the multiple complications that face the practitioner when preparing such canals, such as loss of working length, change of canal path, obturations, perforations, instruments refraction, ledge formation and zipping occurrence due to the difficulty of reaching the entire working length[5] and the accompanying difficulties in completing the remaining therapeutic procedures [6], the use of nickel titanium files, with their varied tapers and high flexibility, gave the practitioner a great ability in maintaining the original curvature of the root canal system [7], especially if the preparation was preceded by creating a glide path for the canal using a glide path-creation nickel titanium files $[8,9]$.

Securing the Glide Path in Endodontic therapy became one of the recommended basic principles for obtaining as safe preparation as possible [10], wither the glide path was secured using manual or mechanical files [11] and is defined as a smoothwalled path extending from the canal orifice and ending with the physiological apical foramen.

this is achieved when the file by which the glide path was created enters the entire canal length smoothly and without any impedances [12], And that will ease the canal preparation procedures as it provides a path that allows larger files to easily enter the canal $[13,14]$. Hence, the idea of the research emerged in evaluating the ability of mechanical patency -to create the glide path- in maintaining the original shape and centric of the canal during canal preparation using three single mechanical preparation systems, that is in one of the most difficult cases in endodontic treatment, which is the double curved canals.

So, the aim of the research is to evaluate the effectiveness of the R-Pilot system in creating the glide path within the simulated double curved canals in terms of its ability to maintain -the centric and the shape of the canal compared with manual patency.

\section{Material and Methods}

Study sample:

60 double curved canals were used in this study, each canal made of transparent resin and had two coronal and apical curvature with diameter and taper corresponding to the ISO measurement, the apex measurement was 0.15 , a taper of $2 \%$, and a working length of 16 $\mathrm{mm}$ for each canal.

Depending on the used patency technique The sample split into two groups A and B, manually and mechanically respectively, each of them had 30 canals $(n=30)$. Each subgroup was split to three basic groups and each of them was named after the used preparation system type $((\mathrm{O}, \mathrm{X}, \mathrm{H}))$, each preparation system group contains 10 canals, the blocks were also numbered in each group from 1 to 10.

\section{Study design:}

A laboratory study to evaluate the effectiveness of three single-file preparation systems in preparing artificial double curved canals made of transparent resin, after performing mechanical or manual patency and studying the changes and the complications that occur when preparing such canals to determine the best patency 
륭ㄷㅂ vol 9 No 1 (2021) Dol 10.5195/d3000.2021.131

pattern and the best preparation system used.

Used Materials:

Three different preparation systems were used, One Curve, Hyflex EDM, XP Endo shaper, RPilot mechanical patency system and manual Stainless-steel K-Files were used in accordance with specifications specified earlier in the sample group (Figure 1-A), a privet hand-made device was used to fix the resin blocks, a singledimensional fixed-angle camera was used for all samples, during which time a unified fixed angle camera was used. (Figure 1-B).

The practical steps of the research:

These resin blocks, which contain the double curved canals, were fixed within a specially designed base for this study and solar images were taken under the same conditions in terms of dimension, angle and lighting using a digital camera, then the study was conducted on 10 levels that were determined perpendicular to the longitudinal axis of the canal where These points were determined based on the initial image, and each canal was divided into three areas (the straight coronal area, the first curvature, and the apical curvature).

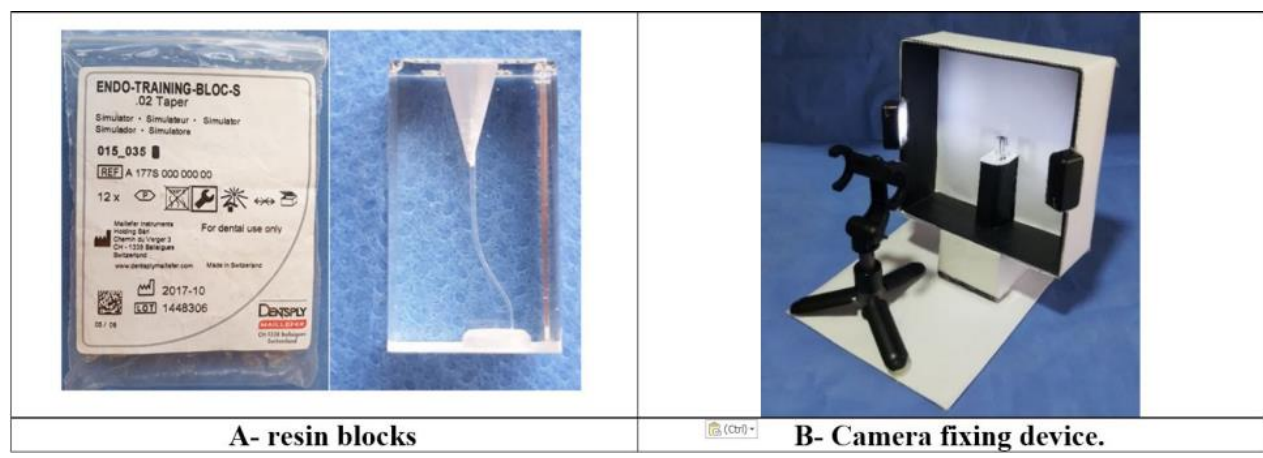

Figure 1: (A) The stimulated resin canals, (B) photo fixing device.

By identifying these levels and areas, we can study what will happen along the length of the canal, depending on the following criteria, where the change in the natural shape of the canal is evaluated according to the following:

Amount of deviation (expressing the centric of the canal): the maximum value of the removed resin width from two sides.

- $\quad$ Centering Ratio (rate of the canal centric).

\section{Results}

The research sample consisted of 600 different sections determined in 60 simulated double curved canals. The sample was divided into two groups according to the glide path creation technique ( $R$ Pilot, and manual files), and each group was divided into three subgroups (One Curve preparation system, XP Endo Shaper preparation system, Hyflex EDM preparation system). In addition,
10 different sections were made in each simulated canal; the sections were divided according to the studied area to the apical curvature area; the first curvature area, and the straight coronal area.

Studying the deviation from the canal centric:

Table No. 1 shows the various between the two means of the deviation value from the canal centric after creating the glide path using the R-Pilot system or by using manual files. A student test was performed for the independent samples and there were no significant differences in all the studied areas, as the significance level value was greater than (0.05)) for all groups.

An ANOVA test was performed to determine the differences between the used preparation systems (One Curve, XP Endo Shaper, and Hyflex EDM) in each of the studied areas in terms of 
Vol 9 No 1 (2021) DOI 10.5195/d3000.2021.131

\begin{tabular}{|c|c|c|c|c|c|c|c|c|c|c|}
\hline Method & & $\mathrm{N}$ & Mean & SD & Min & Max & $\begin{array}{l}\text { Means } \\
\text { difference }\end{array}$ & T-value & P-value & Sig \\
\hline \multirow{2}{*}{$\begin{array}{l}\text { Apical } \\
\text { curvature }\end{array}$} & R-Pilot & 120 & -0.01 & 0.84 & -2.25 & 2.77 & 0.07 & 0.59 & 0.556 & \\
\hline & Hand files & 120 & -0.07 & 0.87 & -2 & 2.39 & & & & \\
\hline \multirow{2}{*}{$\begin{array}{l}\text { First } \\
\text { curvature }\end{array}$} & R-Pilot & 120 & 0.46 & 0.73 & -1.22 & 2.39 & 0.04 & 0.395 & 0.693 & \\
\hline & Hand files & 120 & 0.43 & 0.73 & -1.71 & 2.71 & & & & \\
\hline \multirow{2}{*}{$\begin{array}{l}\text { Coronal } \\
\text { curvature }\end{array}$} & R-Pilot & 60 & -0.2 & 1.04 & -2.78 & 3.62 & 0.12 & 0.706 & 0.482 & \\
\hline & Hand files & 60 & -0.32 & 0.75 & -2.74 & 1.35 & & & & \\
\hline \multirow[t]{2}{*}{ Full canal } & R-Pilot & 300 & 0.14 & 0.88 & -2.78 & 3.62 & 0.06 & 0.911 & 0.363 & \\
\hline & Hand files & 300 & 0.08 & 0.85 & -2.74 & 2.71 & & & & \\
\hline
\end{tabular}

sig: significance.

the amount of deviation from the canal centric after preparation.

When using the R -Pilot system to create the glide path, a statistically significant difference was found in the first curvature area (0.001), the coronal area (0.043) and the entire canal (0.007). Whereas, with the use of manual files, there was no significantly important difference except in the coronal area (0.044) (Table No. 2).

The Bonferroni test was used to compare the deviation amount variable in the canal centric after preparation between two different preparation systems separately, according to different studied areas and different glide path creation techniques. (Table No. 3) shows the results of the values of this test.

Studying the rate of preserving the canal centric:

Table No. 4 shows the mean and the standard deviation of the rate of preserving the canal centric after creating the glide path, the independent sample t-test was also used to study the existence of a significant difference between the R-Pilot system and the manual files, as it found a significant difference between the two preparation systems at each of the coronal area and the entire canal $(0.000,0.002)$, respectively, while there was no significant difference in both the apical and the first curvature area.

Figure No. 2 demonstrated the canal centric preserving rate value in the research sample, the values were higher in all groups, which used the R-Pilot system. 
Table 2: studying the deviation from the canal centric ANOVA test.

\begin{tabular}{|c|c|c|c|c|c|c|c|c|c|c|}
\hline Method & & Preparation system & $\mathrm{N}$ & SD & SE & Min & Max & F-value & P-value & Sig \\
\hline \multirow[t]{12}{*}{ R-Pilot } & \multirow{3}{*}{$\begin{array}{l}\text { Apical } \\
\text { curvature }\end{array}$} & One Curve & 40 & 0.2 & 1.35 & -3.22 & 3.39 & 0.314 & 0.731 & \\
\hline & & XP Endo Shaper & 40 & -0.1 & 1.55 & -3.41 & 2.84 & & & \\
\hline & & Hyflex EDM & 37 & 0.05 & 2.11 & -3.73 & 3.36 & & & \\
\hline & \multirow{3}{*}{$\begin{array}{l}\text { First } \\
\text { curvature }\end{array}$} & One Curve & 40 & 1.27 & 1.12 & -0.77 & 3.64 & 7.391 & 0.001 & * \\
\hline & & XP Endo Shaper & 40 & 0.48 & 1.28 & -2.31 & 2.65 & & & \\
\hline & & Hyflex EDM & 40 & 1.45 & 1.2 & -1.53 & 3.87 & & & \\
\hline & \multirow{3}{*}{$\begin{array}{l}\text { Coronal } \\
\text { curvature }\end{array}$} & One Curve & 20 & -0.37 & 0.92 & -1.79 & 1.92 & 3.323 & 0.043 & * \\
\hline & & XP Endo Shaper & 20 & -0.83 & 1.02 & -3.05 & 1.18 & & & \\
\hline & & Hyflex EDM & 20 & 0.07 & 1.34 & -1.53 & 4.44 & & & \\
\hline & \multirow[t]{3}{*}{ Full canal } & One Curve & 100 & 0.52 & 1.34 & -3.22 & 3.64 & 5.103 & 0.007 & * \\
\hline & & XP Endo Shaper & 100 & -0.01 & 1.43 & -3.41 & 2.84 & & & \\
\hline & & Hyflex EDM & 97 & 0.63 & 1.75 & -3.73 & 4.44 & & & \\
\hline \multirow{12}{*}{$\begin{array}{l}\text { Hand } \\
\text { files }\end{array}$} & \multirow{3}{*}{$\begin{array}{l}\text { Apical } \\
\text { curvature }\end{array}$} & One Curve & 40 & 0.45 & 1.75 & -2.86 & 5.28 & 0.435 & 0.648 & \\
\hline & & XP Endo Shaper & 40 & 0.03 & 2.2 & -3.95 & 4.57 & & & \\
\hline & & Hyflex EDM & 40 & 0.42 & 2.64 & -4.44 & 9.54 & & & \\
\hline & \multirow{3}{*}{$\begin{array}{l}\text { First } \\
\text { curvature }\end{array}$} & One Curve & 40 & 1.65 & 0.92 & -0.61 & 3.19 & 2.723 & 0.07 & \\
\hline & & XP Endo Shaper & 40 & 1.06 & 1.21 & -1.76 & 3.16 & & & \\
\hline & & Hyflex EDM & 40 & 1.51 & 1.41 & -2.49 & 3.85 & & & \\
\hline & \multirow{3}{*}{$\begin{array}{l}\text { Coronal } \\
\text { curvature }\end{array}$} & One Curve & 20 & 0.28 & 0.78 & -1.28 & 1.27 & 3.297 & 0.044 & * \\
\hline & & XP Endo Shaper & 20 & -0.23 & 1.08 & -2.16 & 1.45 & & & \\
\hline & & Hyflex EDM & 20 & -0.4 & 0.72 & -2.11 & 0.59 & & & \\
\hline & \multirow[t]{3}{*}{ Full canal } & One Curve & 100 & 0.9 & 1.43 & -2.86 & 5.28 & 2.123 & 0.121 & \\
\hline & & XP Endo Shaper & 100 & 0.39 & 1.74 & -3.95 & 4.57 & & & \\
\hline & & Hyflex EDM & 100 & 0.69 & 2.04 & -4.44 & 9.54 & & & \\
\hline
\end{tabular}


Vol 9 No 1 (2021) DOI 10.5195/d3000.2021.131

Table 2: sig: significance.

*: statistically significant.

Table 3: Studying the deviation from the canal centric after preparation, Bonferroni test

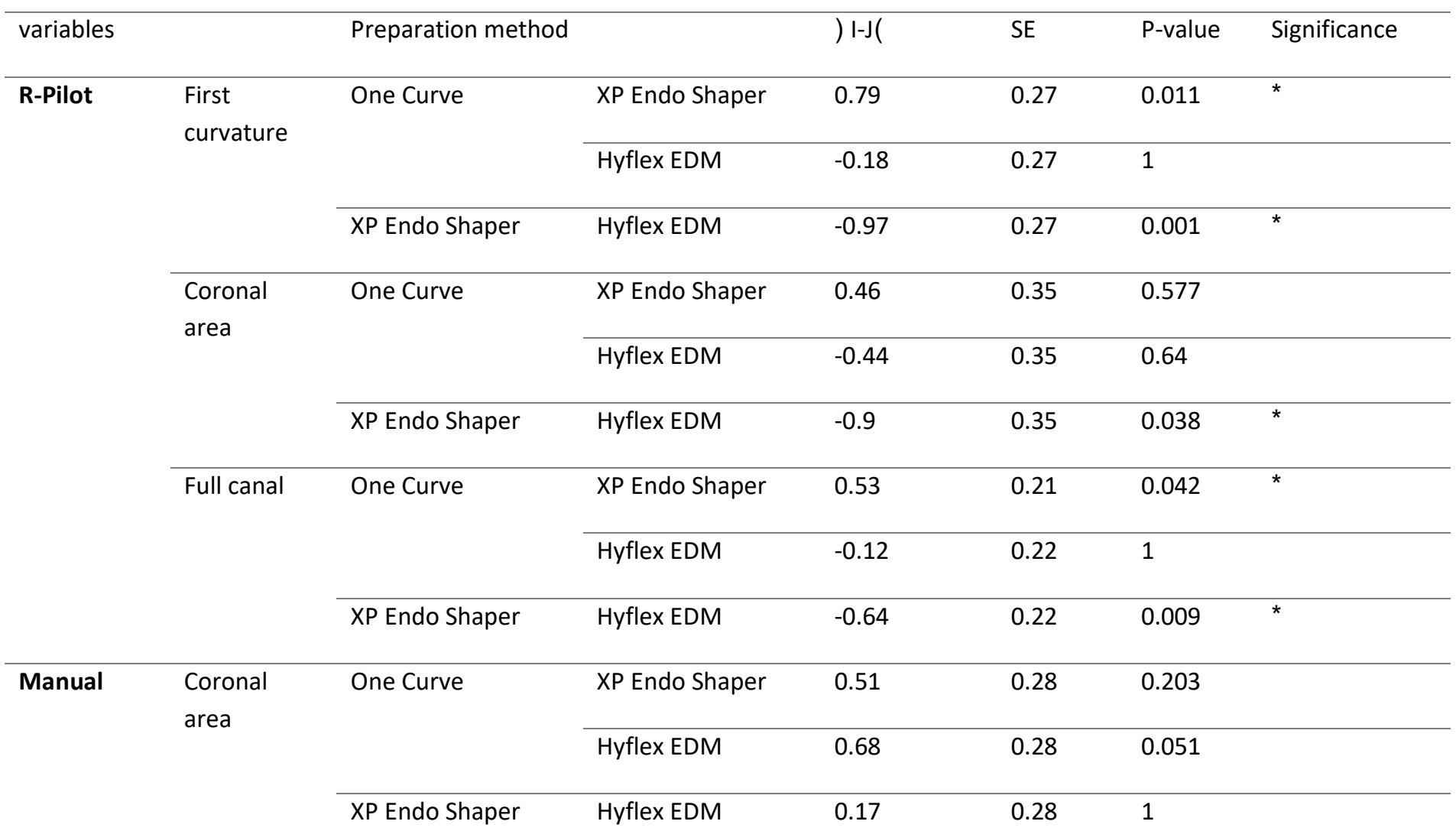

*: statistically significant 
Table 4: the rate of preserving the canal centric after glide path

\begin{tabular}{|c|c|c|c|c|c|c|c|}
\hline Variables & & $\mathrm{N}$ & Mean & SD & T-value & P-value & Significance \\
\hline \multirow[t]{2}{*}{ Apical curvature } & R-Pilot & 120 & 0.493 & 0.285 & 0.754 & 0.451 & \\
\hline & manual & 120 & 0.466 & 0.268 & & & \\
\hline \multirow[t]{2}{*}{ First couverture } & R-Pilot & 120 & 0.53 & 0.258 & 1.653 & 0.1 & \\
\hline & Manual & 120 & 0.474 & 0.265 & & & \\
\hline \multirow[t]{2}{*}{ Coronal area } & R-Pilot & 60 & 0.713 & 0.215 & 4.158 & 0.000 & * \\
\hline & manual & 60 & 0.529 & 0.268 & & & \\
\hline \multirow[t]{2}{*}{ Full canal } & R-Pilot & 300 & 0.552 & 0.274 & 3.173 & 0.002 & * \\
\hline & Manual & 300 & 0.482 & 0.267 & & & \\
\hline
\end{tabular}

*: statistically significant

\section{Discussion}

The importance of mechanical preparation of root canals comes not only in terms of removing all live and dead tissues inside the root canal, but also from the importance of creating a sufficient place to allow the entry of both irrigating fluids, intra-canalicular dressing, and filling materials in order to complete their role in disinfection the root canal system and seal it tightly [15] while preserving the original shape of the canal [16].

Where canals curvature and canal anatomical anomalies are one of the most important challenges faced by the practitioner during endodontic treatment, due to the many potential complications during treatment such as zipping occurrence, deviation of the canal, opening or changing in the shape or location of the apex, which causes subsequent failure of the endodontic treatment [17].

Despite the advantages and the massive flexibility of nickeltitanium mechanical files, securing an initial glide path on the canal before using the mechanical preparation instruments is considered among the recommended matters, whether manually or by using glide path creation mechanical files [18].

In this study, double curved resin blocks were used instead of using natural teeth, due to the ineffectiveness of those last for comparison between preparation systems, as differences, even minor ones, between those teeth may make clear variances in results more than these made by different preparation systems [19], thus giving the resin blocks the possibility of unification the required standards in the study sample in terms of length, hardness, manufacture's material, curvature radius and angle $[20,21]$, and, although it may not significantly reflect the clinical aspect due to the difference between the hardness of the dentin and the resin [22], though, it is a good and valid measure for studying different preparation systems $[23,24]$.

The results of our study showed that when comparing the two methods of creating a glide path 
Vol 9 No 1 (2021) Dol 10.5195/d3000.2021.131

'with an R-Pilot mechanical file and using manual K-Files up to the size of \# 20' in studying the amount of deviation of the canal centric, by subtracting the output of the removed resin in the right side, -in each level of the study levels- from the removed resin in the left side, in two stages after creating the glide path and after preparation, our study did not show a significant difference in the deviation amount from The canal centric after creating the glide path, regardless the followed method.

Whereas the study of the rate of preserving the canal centric after the glide path creating step, there were no clear differences between the two methods. Thus, the two methods were equal in preserving the canal centric in the apical curvature area. However, in the first curvature area, the coronal area and in the entire canal, our study had proved that the glide path creation using R-Pilot mechanical file is better than creating it using manual files.

Our study showed that the deviation amount values in the centric of the canal after preparing the apical area did not differ according to the different preparation systems applied and the used method to create the glide path.

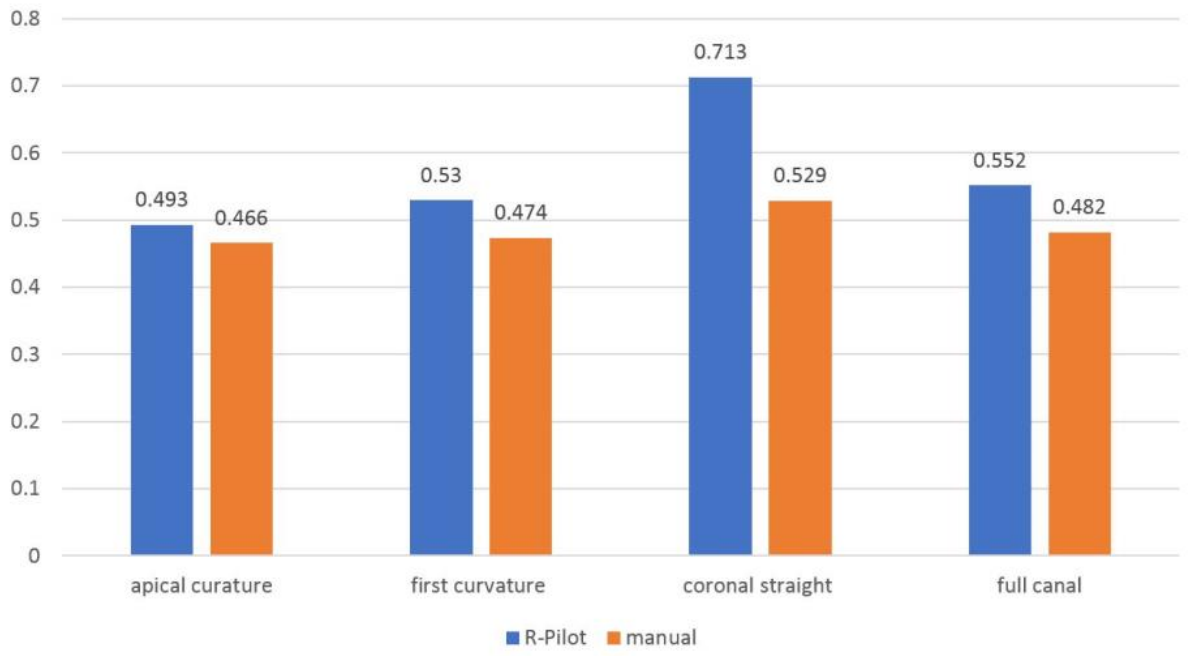

Figure 2: Average value for canal centric after creating the glide path using different methods.

As for in the first curvature area, coronal area and the entire canal, the XP Endo Shaper preparation group outperformed which made her the smallest among the Preparation groups compared to the One Curve preparation system group and the Hyflex EDM preparation system group. This can be explained by the difference in tapering between the singlefiles used in the preparation as the XP Endo Shaper has the smallest taper between them.

Our study agreed with the results of a previous study [25], which compared different types of glide path creation using single-file mechanical files (R-Pilot - Wave One Gold Glider - ProGlide) in terms of the ability of R-Pilot file to maintain the shape and centric of the canal. Compared to other glide path creation systems.
We also agreed with another study [26], which compared five different types of mechanical preparation systems on a $120 \mathrm{~S}$ shaped manufactured canal sample with or without glide path creation and showed that the files with smaller taper were more preserver on the shape and the centric of the canal, where (Schilder H 1974) [27] showed that the elasticity and hardness of the file varies according to the size, diameter and taper of the used instrument. Therefore, instruments with smaller tapering led to better results in terms of maintaining centric.

Also, when comparing this study with that of (Alfadley et al, 2020) we show the superiority of the XPEndo Shaper over Wave One Gold in terms of maintaining the centrality and the shape of the 
canal in severely curved canals; due to the mixed-made nature of XP-Endo Shaper alloy, where the elasticity of the alloy may have the largest influence on the mechanical performance and behavior of the file upon preparation [16].

While when comparing the Hyflex EDM Preparation system in the study [28] with Protaper Next, the first protagonist outperformed the others and had the best results in terms of conserving the centeralization of the canals; and this may be due to the difference in the study design and the systems used to compare each other.

As for the One Curve preparation system, it is considered a recent file. Until now, there are only two studies that discussed susceptibility formation when studying it. Our study agreed with previous study [29], which compared four preparation systems in an 80 curved mesial canal sample, so the used preparation systems had close results. In terms of preserving the shape and the centric of the canal, the One Curve preparation system showed similar results to the other systems, which can be explained by its high flexibility due to the heat-treated C-Wire alloy.
The same thing with the R-Pilot mechanical file, which is considered very recent, and despite the presence of many studies that discussed its ability to resist efforts in various forms and degrees of curvature of the root canals, until now there was only one study dealt with the ability of maintaining the shape and the centric of the canal.

It is important to mention that in this research, we studied the ability to maintain the shape and the centric of the canal only. The absence of differences between the glide path creation systems does not mean neglecting the importance of mechanical patency, including speed, reducing the effort imposed on the practitioner, especially in curved canal and safety in preparation.

\section{Conclusion}

Creating a glide path in one of the described methods, emphasizing the importance of mechanical patency in terms of speed and reducing the effort and burden imposed on the practitioner compared to the use of manual files.

Emphasis on the one-time use of mechanical preparation systems whenever possible, especially in canals with anatomical anomalies, to avoid complications resulting from preparation.

Consider depending on high flexibility and smaller tapering preparation systems for preparing curved root canals with complex anatomical anomalies. XP Endo shaper had lower deviation values and more ability to save the canal's shape and centric.

\section{Conflicts of interest}

The authors declare no competing interest.

\section{References}

1. Comparative Evaluation of Root Canal Transportation by Three NiTi Single-File Systems in Curved Canals: A Cone Beam Computed Tomography Study. Saberi E, Farhad-Mollashahi N, Bijari S, Daryaeian M. Int J Dent. 2018 May;14:4151692. doi: 10.1155/2018/4151692. PMID: 29861728.

2. Shaping ability of ProTaper Universal, WaveOne and ProTaper Next in simulated L-shaped and Sshaped root canals. Wu $\mathrm{H}$, Peng $\mathrm{C}$, Bai Y, Hu X, Wang L, Li C. BMC Oral Health. 2015 Mar;15(1):27. doi: 10.1186/s12903-015-0012-z.

PMID: 25886847.

3. Analysis of $\mathrm{Ni}-\mathrm{Ti}$ versus stainless steel instrumentation in resin simulated canals. Coleman CL, Svec TA. J Endod. 1997 Apr;23(4):232-235. doi: 
10.1016/S0099-2399(97)80053-2. PMID: 9594772.

4. Bending resistance and cyclic fatigue life of Reciproc Blue, WaveOne Gold, and Genius files in a double (S-shaped) curved canal. Özyürek T, Gündoğar $M$, Yılmaz K, Uslu G. J Dent Res Dent Clin Dent Prospects. 2017 Fall;11(4):241246. doi: 10.15171/joddd.2017.042. PMID: 29354251.

5. Safe root canal preparation using reciprocating nickel-titanium instruments. Ha JH. Restor Dent Endod. 2015 Aug;40(3):253-254. doi: $\quad 10.5395 /$ rde.2015.40.3.253. PMID: 26295031.

6. The effect of preparation procedures on original canal shape and on apical foramen shape. Weine FS, Kelly RF, Lio PJ. J Endod. 1975 Aug;1(8):255-262. doi: 10.1016/S0099-2399(75)80037-9. PMID: 10697472.

7. The shaping effects of three nickel-titanium rotary instruments in simulated S-shaped canals. Yoshimine $\mathrm{Y}$, Ono M, Akamine A. J Endod. 2005 May;31(5):373-275. doi:

10.1097/01.don.0000140568.4046 2.43. PMID: 15851932.

8. Shaping ability of ProTaper NEXT, ProTaper Universal and iRace files in simulated S-shaped canals. Hiran-us S, Pimkhaokham S, Sawasdichai J, Ebihara A, Suda H. Aust Endod J. 2016 Apr;42(1):3236. doi: 10.1111/aej.12117. PMID: 26420685.
9. Apical root canal transportation and remaining dentin thickness associated with ProTaper Universal with and without PathFile. Zanette $F$, Grazziotin-Soares R, Flores ME, Camargo Fontanella VR, Gavini G, Barletta FB. J Endod. 2014 May;40(5):688-693. doi: 10.1016/j.joen.2013.09.001. PMID: 24767565.

10. Comparison of glide paths created with K-files, PathFiles, and the ProGlider file, and their effects on subsequent WaveOne preparation in curved canals. Zheng L, Ji X, Li C, Zuo L, Wei X. BMC Oral Health. 2018 Aug 29;18(1):152. doi:

10.1186/s12903-018-0614-3.

PMID: 30157822.

11. Comparison among manual instruments and PathFile and Mtwo rotary instruments to create a glide path in the root canal preparation of curved canals. Alves Vde $\mathrm{O}$, Bueno $\mathrm{CE}$, Cunha RS, Pinheiro SL, Fontana CE, de Martin AS. J Endod. 2012 Jan;38(1):117120. doi:

10.1016/j.joen.2011.10.001. PMID: 22152634.

12. Endodontic update 2006. West J. J Esthet Restor Dent. 2006;18(5):280-300. doi:

$10.1111 / \mathrm{j} .1708-$

8240.2006.00039.x.

PMID: 16987326.

13. A dozen ways to prevent nickel-titanium rotary instrument fracture. Di Fiore PM. J Am Dent Assoc. 2007 Feb;138(2):196-201; quiz

249. doi: 10.14219/jada.archive.2007.0136. PMID: 17272374.

14. Peters O A, Koka R S (2009) Preparation of coronal and radicular spaces.

15. Comparison of Shaping Ability of Different Single-File Systems Using Microcomputed Tomography. Elashiry MM, Saber SE, Elashry SH. Eur J Dent. 2020 Feb;14(1):70-76. doi: 10.1055/s0040-1701393. PMID: 32005040.

16. Shaping Ability of XP Endo Shaper File in Curved Root Canal Models. Alfadley A, Alrajhi A, Alissa $H$, Alzeghaibi F, Hamadah L, Alfouzan K, Jamleh A. Int J Dent. 2020 Feb 17;2020:4687045. doi: 10.1155/2020/4687045. PMID: 32148503 .

17. Canal transportation and centering ratio after preparation in severely curved canals: analysis by micro-computed tomography and double-digital radiography. Poly $A$, AlMalki F, Marques F, Karabucak B. Clin Oral Investig. 2019 Dec;23(12):4255-4262. doi: 10.1007/s00784-019-02870-8. PMID: 30834991.

18. Higher Speed and No Glide Path: A New Protocol to Increase the Efficiency of XP Shaper in Curved Canals-An In Vitro Study. Webber M, Piasecki L, Jussiani El, Andrello AC, Dos Reis PJ, Azim KA, Azim AA. J Endod. 2020 Jan;46(1):103-109. doi: 10.1016/j.joen.2019.10.014. PMID: 31761330. 
19. hanges in root canal geometry after preparation assessed by high-resolution computed tomography. Peters OA, Laib A, Göhring TN, Barbakow F. C. J Endod. 2001 Jan;27(1):1-6. doi: 10.1097/00004770-20010100000001. PMID: 11487156.

20. A microcomputed tomography evaluation of the shaping ability of three thermallytreated nickel-titanium rotary file systems in curved canals. Huang $Z$, Quan J, Liu J, Zhang W, Zhang X, Hu $X$. J Int Med Res. 2019 Jan;47(1):325-334. doi: $10.1177 / 0300060518801451$.

PMID: 30282507.

21. Transportation assessment in artificial curved canals after instrumentation with Reciproc, Reciproc Blue, and XP-endo Shaper Systems. Pacheco-Yanes J, Gazzaneo I, Pérez AR, Armada L, Neves MAS. J Investig Clin Dent. 2019 Aug;10(3):e12417. doi: 10.1111/jicd.12417. PMID: 30955238.

22. Comparative analysis of canal transportation and centring ability of three $\mathrm{Ni}-\mathrm{Ti}$ rotary endodontic systems: Protaper $^{\circledR}$, MTwo ${ }^{\circledR}$ and Revo-S ${ }^{\mathrm{TM}}$, assessed by micro-computed tomography. Vallaeys K, Chevalier V, ArbabChirani R. Odontology. 2016 Jan;104(1):83-88. doi: 10.1007/s10266-014-0176-z.

PMID: 25248755.

23. Shaping ability of 4 different single-file systems in simulated S-shaped canals. Saleh
AM, Vakili Gilani P, Tavanafar S, Schäfer E. J Endod. 2015 Apr;41(4):548-552. doi: 10.1016/j.joen.2014.11.019.

PMID: 25576206.

24. A comparison of the shaping ability of three nickeltitanium rotary instruments: a micro-computed tomography study via a contrast radiopaque technique in vitro. Wei $Z$, Cui Z, Yan P, Jiang H. BMC Oral Health. 2017 Jan 9;17(1):39. doi: 10.1186/s12903-016-0326-5. PMID: 28068971.

25. Microcomputed

Assessment of Transportation, Centering Ratio, Canal Area, and Volume Increase after Single-file Rotary and Reciprocating Glide Path Instrumentation in Curved Root Canals: A Laboratory Study. Aydın ZU, Keskin NB, Özyürek T, Geneci F, Ocak M, Çelik HH. J Endod. 2019 Jun;45(6):791-796. doi: $\quad 10.1016 / j$.joen.2019.02.012. PMID: 30935620.

26. Shaping ability of different nickel-titanium systems in simulated S-shaped canals with and without glide path. Bürklein $S$, Poschmann T, Schäfer E. J Endod. 2014 Aug;40(8):1231-1234. doi: 10.1016/j.joen.2014.01.043.

PMID: 25069939.

27. Cleaning and shaping the root canal. Schilder H. Dent Clin North Am. 1974 Apr;18(2):269296. PMID: 4522570.

28. A Micro-computed Tomography Evaluation of the Shaping Ability of Two Nickel- titanium Instruments, HyFlex EDM and ProTaper Next. Venino PM, Citterio CL, Pellegatta A, Ciccarelli M, Maddalone M. J Endod. 2017 Apr;43(4):628-632. doi: 10.1016/j.joen.2016.11.022.

PMID: 28215346.

\section{Micro-Computed}

Tomographic Evaluation of Canal Transportation and Centering Ability of 4 Heat-Treated NickelTitanium Systems. Razcha C, Zacharopoulos A, Anestis D, Mikrogeorgis G, Zacharakis G, Lyroudia K. J Endod. 2020 May;46(5):675-681. doi: 10.1016/j.joen.2020.01.020.

PMID: 32171564. 